\title{
Tumor Treating Fields Therapy
}

National Cancer Institute

\section{Source}

National Cancer Institute. Tumor Treating Fields Therapy. NCI Thesaurus. Code C146882.

A type of electromagnetic field therapy that uses low-intensity, intermediate-frequency alternating electrical fields to a target area to induce selective toxicity to proliferating cells. 